\title{
COVID Sniffer Dogs: Technical and Ethical Concerns
}

\author{
Biagio D'Aniello ${ }^{1 *}$, Claudia Pinelli ${ }^{2}$, Mario Varcamonti ${ }^{1}$, Marcello Rendine ${ }^{3}$, \\ Pietro Lombardi ${ }^{4}$ and Anna Scandurra ${ }^{1}$
}

${ }^{1}$ Department of Biology, University of Naples Federico II, Naples, Italy, ${ }^{2}$ Department of Environmental, Biological and Pharmaceutical Sciences and Technologies, University of Campania "L. Vanvitelli", Caserta, Italy, ${ }^{3}$ Department of Clinical and Experimental Medicine, University of Foggia, Foggia, Italy, ${ }^{4}$ Department of Veterinary Medicine and Animal Production, University of Naples Federico II, Naples, Italy

Keywords: SARS-CoV-2, COVID-19, dogs, volatile organic compounds, detection dogs

\section{OPEN ACCESS}

Edited by:

Emily Patterson-Kane,

Independent Researcher, Rolling

Meadows, United States

Reviewed by:

Lucia Lazarowski,

Auburn University, United States

Matt Smear,

University of Oregon, United States

Cynthia M. Otto,

University of Pennsylvania,

United States

*Correspondence:

Biagio D'Aniello

biagio.daniello@unina.it

Specialty section:

This article was submitted to Animal Behavior and Welfare,

a section of the journal

Frontiers in Veterinary Science

Received: 19 February 2021

Accepted: 21 May 2021

Published: 21 June 2021

Citation:

D'Aniello B, Pinelli C, Varcamonti M.

Rendine $M$, Lombardi $P$ and

Scandurra A (2021) COVID Sniffer

Dogs: Technical and Ethical Concerns.

Front. Vet. Sci. 8:669712.

doi: 10.3389/fvets.2021.669712
Hindu medicine showed us that some diseases can alter a humans' scent. Some diseases emit specific volatile organic compounds (VOCs) from exudates, which can be used as a diagnostic tool (1). Recently, occidental culture has started to identify diseases through olfaction, including smallpox (2). Some studies have underlined that humans can identify individuals with bacteria-derived endotoxins through sweat, considering the smell of the sweat unpleasant (3). This olfactory cue could activate a social avoidance, helping to stay far from infected people, thus limiting the contagion in humans, as well as in other animals (4). A human's sense of smell is probably underestimated (5), but it is undoubtedly not capable enough to identify pathogens in people with subliminal changes in odor.

While humans may not be able to detect these subtle odor changes, dogs are capable. They can smell different molecules from the human body released during some emotional states (6-9), and they can be trained to give specific signals when identifying an olfactory signature (i.e., alert signal). Dogs are currently used as special sensors to detect VOCs (10). They have been successfully trained to detect several metabolic conditions and diseases in humans, including hypoglycemia and hyperglycemia $(11,12)$, epileptic seizures (13), cancers (14), and bacterial and viral infections (15). However, despite the undoubted individual abilities of trained animals, we are still far from a detailed understanding of what exactly the dog responds to and the possibility of generalizing certain abilities to all dogs.

It has been shown in recent studies that dogs can detect people infected with SARS-CoV-2 (16). The use of dogs for this purpose could be critical during emergencies as well as when diagnostic technologies require a long time to be applied. Thus, the dog could be the best detection device in these cases (17) as it represents a faster method of identifying infected people by a non-invasive procedure. Moreover, the use of dogs would allow operators to avoid contact with infected individuals. Though medical detection dogs could be very expensive to train (18), they could test hundreds of people per day, reducing reagent costs.

In this opinion article, we questioned whether there is sufficient scientific support to justify the training and use of dogs as biological detector systems for SARS-CoV-2 in reasonable time frames and safety. To warrant human and dog health, we analyzed the recent scientific literature and discussed different technical and ethical problems with the involvement of dogs for detecting SARS-CoV-2 in people: the "context-shift effect," the overlap of VOC profiles in different diseases and odors that may occasionally co-occur, the procedure to collect samples, and the possible role of the animals as vectors in a zoonotic scenario.

The SARS-CoV-2 pandemic stimulated scientific inquiries on the ability of dogs to recognize the smell of infected human samples. Grandjean et al. (19) trained six detection dogs in recognizing the smell of SARS-CoV-2-infected people by using armpit sweat samples. Their proof-of-concept study concluded that dogs can detect subjects with SARS-CoV-2 with a very high success rate 
(ranging between 76 and 100\%). Another scientific study tested the effectiveness of dogs in distinguishing saliva samples and tracheobronchial secretions from SARS-CoV-2 patients with clinical symptoms (20). The authors demonstrated that dogs were able to master the task with high rates of sensitivity (average $82.63 \%$ ) and specificity (average 96.35\%) after a week of training. A third study trained dogs to recognize SARS-CoV-2-infected people from respiratory samples (i.e., saliva, nasopharyngeal swabs or aspirates, and tracheal aspirates) obtained from subjects with mild, moderate, or severe symptomatology (21). Also, in this case, the results were very promising, with the testing procedure reaching $95.5 \%$ sensitivity and $99.6 \%$ specificity. These studies showed the high efficacy of dogs in recognizing infected people, thus making them useful tools for a very quick screening in crowded places, such as airports and schools. The scientific results have aroused considerable popular enthusiasm, as pointed out by the media, which consider the dogs easy to train and to operate in work contexts.

Besides these advantages, several technical and ethical concerns may occur by using the dogs as sensors of subjects infected by SARS-CoV-2, which seem poorly considered by media and sometimes underestimated in scientific papers. The scientific studies, while demonstrating the effectiveness of the detection dogs for the SARS-CoV-2, have been very cautious in suggesting the use of their results to train dogs for operative purposes, pointing out several pitfalls. Despite that, it seems that the unsolved issues have not reached the practitioners, and therefore, several canine centers are training and using dogs to detect SARS-CoV-2 infected subjects. According to the present scientific evidence, we believe that this approach is not justified at the moment, for several technical and ethical concerns.

The major problem is that no data are available on the performance of dogs in the field as the application of the models in the laboratory studies has not been scientifically tested in work contexts, thus making the effectiveness of dogs questionable. When animals that learned to perform a behavior under a stimulus in a context are moved to a new context, the performance generally drops, which is known as the "contextshift effect" (22) and maybe reflects the loss of information acquired to achieve the goal. This effect has been observed in dogs highly trained for detecting explosives (23). Additionally, a study on detection dogs for lung cancer patients found that by shifting from a hospital to another location, the dogs' performance was significantly reduced, decreasing sensitivity and increasing the occurrence of false positives (24).

The recognition of the VOCs produced by the viral infection presents some difficulties due to the biology of the infection processes, which induce in the host the production of additional VOCs. Generally, viruses do not have their own metabolism; thus, the elicited VOCs could only arise from the inflammatory responses of the infected host (25). It is unknown if SARS-CoV-2 induces changes in VOCs sharing no commonalities with other inflammatory diseases and whether new variants have the same effect in terms of odor changes. Some of the VOCs produced in a single cell line of the infective viruses H9N2, H6N2, and
H1N1 appeared selective for each virus, but a plethora of several other non-specific VOCs were present (26). A study on breath analysis using multi-capillary column-ion mobility spectrometry showed that it is possible to discriminate between influenza $\mathrm{A}$ and SARS-CoV-2 infections based on the different VOC profiles, although specific VOCs were not identified (27). The authors suggested that dogs could be used to successfully discriminate SARS-CoV-2 infection from other infective diseases. It has been demonstrated that dogs can discriminate VOCs caused by similar virus infections, such as bovine viral diarrhea virus, bovine herpesvirus, and bovine parainfluenza virus (28). Nevertheless, based on previous studies, it is not possible to know for sure if dogs could be confused when detecting between SARS-CoV-2 variants and between variants and other viruses.

In addition to the VOC discrimination problems in infected individuals, another confounding factor could be represented by the overlap of biochemical signals. This phenomenon could confuse dogs, decreasing their detection performance, although the specific combination and concentration of the relevant VOCs may be sufficient for a dog to identify a positive sample. The problem becomes more complex when examining VOCs from the human body while keeping control of the dog's conditioning, which is very important when trying to reduce false positives. For example, two dogs in the bioRxiv version of Grandjean et al. (29) study marked positive a sample from a negative woman that was around the ovulation period, when the luteinizing hormone (LH) peaks. Another study reported that SARS-CoV-2-infected men may show increased levels of LH (30), which makes it plausible to assume that dogs could be conditioned on the metabolic change triggered from the LH instead of that elicited from the virus.

An important factor to be carefully analyzed is the collection and the preparation of the experimental samples for the dog's training. Studies testing the skill of dogs to recognize SARSCoV-2-infected biological samples worked with a relatively small number of independent and single samples (19-21). This procedure cannot exclude that dogs could memorize the odor of the person, rather than that elicited by the SARS-CoV- 2 infection. Indeed, the scientific literature recommends avoiding repeated presentation of samples from the same donors to detection dogs (31).

In the available literature, the samples were collected from symptomatic people; thus, it is unclear whether dogs would alert on samples from asymptomatic individuals. Of course, this is the most important aspect when aiming to identify possible virus spreaders. More research is therefore needed to verify whether dogs could identify asymptomatic and pre-symptomatic individuals. A paper published in August 2020 (32) stated that they were testing dogs to identify asymptomatic people, but the results of this project are not yet available, as well as in the case of Vesga et al. (21).

Beyond the technical aspects of using dogs as sensors, there are also ethical concerns related to the zoonotic transmission of SARS-CoV-2. To date, the bat origin of SARS-CoV-2 remains the most probable cause of the pandemic in humans (33), and several natural, farmed, pet, and wild animal species have 
been found infected (34). Minks can have severe symptoms from the infection, and they can die of pneumonia (35). SARS-CoV-2-specific antibodies were not found in 35 animal species tested using double-antigen sandwich ELISA, including dogs and cats (36), but they were detected in dogs and cats by using plaque reduction neutralization tests $(37,38)$. Dogs were significantly more likely to test positive for SARS-CoV2-neutralizing antibodies if living in households with infected humans $(38,39)$, and apart from some negative reports (40), many studies agree that dogs could become infected by humans, although they do not report symptoms from the SARS-CoV-2 infection (41-46). On the other hand, even in healthy humans, most cases were relatively mild or asymptomatic, but older patients and comorbidities could result in severe cases (47). Currently, only a handful of healthy dogs have been studied, and no studies verified the effect of SARS-CoV-2 in old dogs or dogs with other diseases. A study with an artificial infection on five 3-month-old beagles found low susceptibility to SARSCoV-2 (48), but once again, the samples tested were limited. Should SARS-CoV-2 evolve to be a significant clinical infection in dogs is at the moment unknown. The angiotensin-converting enzyme type 2 receptors (the entry point into cells for some coronaviruses, including SARS-CoV-2) of dogs are very similar to those of humans, with an identity of $83 \%$ (49), which does not discharge the risk that dogs could serve as an intermediate host $(44,50)$. Viruses are well-known to evolve in real time, especially when under immunological pressure, to ease their transmission between humans (51) and from animals to humans (52). A new variant found in humans arose in minks (53). We cannot exclude that new variants in humans may become more infectious for dogs and vice versa, nor can we exclude that new variants in dogs could become more efficient by increasing intraspecies and interspecies transmission. In our opinion, there are currently insufficient results to make sure that dogs could not be or become a reservoir species, whereby we should be more cautious before deliberately exposing dogs to SARS$\mathrm{CoV}-2$. One of the most important strategies for limiting the pandemic is to identify the potential virus reservoir to prevent any spillover effects, certainly not to facilitate a potential new reservoir species. There is evidence that experimentally infected cats $(37,48,54)$, hamsters $(55,56)$, ferrets $(48,57)$, and minks (35) may spread SARS-CoV-2, while pigs and some poultry species do not $(48,58,59)$. In some cases, the situation is worrying as bilateral transmission between humans and animals has been proved [i.e., minks $(60,61)]$. Some studies underlined that there is currently no evidence that infected dogs could be a source of infection for humans $(37,46,62,63)$, although further epidemiological investigations are requested before reaching a definitive conclusion (63). Actually, as a precautionary principle, the fact that there is no scientific evidence does not mean that it could not happen. Some studies have not excluded that dogs could play a role in spreading the virus to other dogs and other animals, including humans $(41,43)$. The uncertainty of classifying dogs as non-spreaders violates the rules of infection prevention and control.
The authors of the studies that tested dogs to detect people infected with SARS-CoV-2 have been very careful to avoid the exposure of dogs to infections $(19,21,43)$, and indeed, in their experimental setting, there was no risk to dogs. However, the laboratory conditions are different from those of the operational work. The fact that SARS-CoV-2 is absent from human sweat $(64,65)$ may make dogs safe in laboratory tests, but not in a naturalistic scenario where control is more difficult. Although anatomical sites such as armpits are protected by contamination, the part should be uncovered by the hands of the potentially infected subject, which does not warrant sterility, especially when the person is requested to pick up the sample on their own. Fathizadeh et al. (66) collected forehead sweat samples from positive people, and even after disinfecting the skin with $70 \%$ ethanol, two positive cases were found in up to 25 infected patients. The authors concluded that although patients' sweat does not contain SARS-CoV-2, it can be easily contaminated. In the study by Jendrny et al. (20), the patient samples were inactivated after incubation for $70-72 \mathrm{~h}$ with a chemical compound (i.e., propiolactone) to inactivate the virus. This procedure, while eliminating the risk of contagion, makes faster use of dogs impractical.

To summarize, we reported some suggestions to the problems pointed out in this opinion. Dogs' effectiveness should be tested in different testing environments and naturalistic scenarios to avoid the context-shift effect. It should be a priority to delineate the VOC profiles of the samples of infected people, as collected, using headspace solid-phase microextraction combined with gas chromatography-mass spectrometry, before utilizing them for training the dogs. In the same way, the VOC profiles of the samples should be delineated from non-diseased subjects (67). This procedure would allow comparison of symptomatic and asymptomatic subjects, age classes, sexes, and different parts of the body sample. Although dogs can be trained in the absence of such information, this technical approach is important to allow researchers and stakeholders to control the training at best, thus reaching more suitable performances. The use of VOC-free support materials is recommended to prevent contamination in the results. In the absence of VOC-free gauzes and tubes, these should be pretreated to remove VOC contaminants as described by Cardinali et al. (68). To rule out interindividual differences in body odor, exudates from a large number of different individuals should be collected and mixed (7), or at least different samples should be used for training and testing procedures. To further minimize the chance of dogs memorizing odors from individuals, they should also be trained with the exudates of the same subject collected during both the infective and healthy phases. In that case, it would be necessary to know how long individuals can maintain the odor, especially if matched samples are used. From the reviewed literature, we have a very low chance of SARS$\mathrm{CoV}-2$ contagion by interacting with our pet dogs. However, it is undoubtful that greater awareness is needed for understanding the possible involvement of dogs in virus hosting and spreading, using a broader vision in the One Health approach. We are not proposing to completely abandon the sniffing dog strategy. 
We advocate the precautionary principle and highlight the need for further scientific studies addressing the concerns outlined in this opinion paper before claiming that we can safely use and train dogs effectively to detect SARS-CoV-2-infected people. Particularly, developing a vaccine for dogs could help mitigate the underlined ethical concerns. However, this procedure does not warrant that dogs could serve as a reservoir for the SARS-CoV-2 and develop new variants.

Only after having passed all these scientific steps can we start using dogs in work contexts with more reasonable effectiveness.

\section{REFERENCES}

1. Sushruta. The Sushruta Samhita. ed. K. K. L. Bhishagratna S. L. Bhaduri BL, Io. Kashi Ghose's Lane, Calcutta: Sushruta (1916).

2. Liddell K. Smell as a diagnostic marker. Postgrad Med J. (1976) 52:136-8. doi: 10.1136/pgmj.52.605.136

3. Olsson MJ, Lundström JN, Kimball BA, Gordon AR, Karshikoff B, Hosseini N, et al. The scent of disease: human body odor contains an early chemosensory cue of sickness. Psychol Sci. (2014) 25:817-23. doi: 10.1177/0956797613515681

4. Curtis VA. Infection-avoidance behaviour in humans and other animals. Trends Immunol. (2014) 35:457-64. doi: 10.1016/j.it.2014.08.006

5. McGann JP. Poor human olfaction is a 19th-century myth. Science. (2017) 356:eaam7263. doi: 10.1126/science.aam7263

6. Siniscalchi M, D'Ingeo S, Quaranta A. The dog nose "KNOWS" fear: asymmetric nostril use during sniffing at canine and human emotional stimuli. Behav Brain Res. (2016) 304:34-41. doi: 10.1016/j.bbr.2016.02.011

7. D'Aniello B, Semin GR, Alterisio A, Aria M, Scandurra A. Interspecies transmission of emotional information via chemosignals: from humans to dogs (Canis lupus familiaris). Anim Cogn. (2018) 21:67-78. doi: 10.1007/s10071-017-1139-x

8. D'Aniello B, Fierro B, Scandurra A, Pinelli C, Aria M, Semin GR. Sex differences in the behavioral responses of dogs exposed to human chemosignals of fear and happiness. Anim Cogn. (2021) 24:299-309. doi: 10.1007/s10071-021-01473-9

9. Semin GR, Scandurra A, Baragli P, Lanatà A, D'Aniello B. Inter- and intraspecies communication of emotion: chemosignals as the neglected medium. Animals. (2019) 9:887. doi: 10.3390/ani9110887

10. Rendine M, Fiore C, Bertozzi G, De Carlo D, Filetti V, Fortarezza P, et al. Decomposing human blood: canine detection odor signature and volatile organic compounds. J Forensic Sci. (2019) 64:587-92. doi: 10.1111/1556-4029.13901

11. Hardin DS, Anderson W, Cattet J. Dogs can be successfully trained to alert to hypoglycemia samples from patients with type 1 diabetes. Diabetes Ther. (2015) 6:509-17. doi: 10.1007/s13300-015-0135-x

12. Reeve C, Cummings E, McLaughlin E, Smith S, Gadbois S. An idiographic investigation of diabetic alert dogs' ability to learn from a small sample of breath samples from people with type 1 diabetes. Can J Diabetes. (2020) 44:37-43.e1. doi: 10.1016/j.jcjd.2019.04.020

13. Catala A, Grandgeorge M, Schaff JL, Cousillas H, Hausberger M, Cattet J. Dogs demonstrate the existence of an epileptic seizure odour in humans. Sci Rep. (2019) 9:4103. doi: 10.1038/s41598-019-4 0721-4

14. Jezierski T, Walczak M, Ligor T, Rudnicka J, Buszewski B. Study of the art: canine olfaction used for cancer detection on the basis of breath odour. Perspectives and limitations. J Breath Res. (2015) 9:27001. doi: 10.1088/1752-7155/9/2/027001

15. Angle C, Waggoner LP, Ferrando A, Haney P, Passler T. Canine detection of the volatilome: a review of implications for pathogen and disease detection. Front Vet Sci. (2016) 3:47. doi: 10.3389/fvets.2016.00047

16. ICTV. Naming the 2019 Coronavirus (2021) Available online at: https://talk. ictvonline.org/

17. Hackner K, Pleil J. Canine olfaction as an alternative to analytical instruments for disease diagnosis: understanding "dog personality" to achieve reproducible results. J Breath Res. (2017) 11:1-5. doi: 10.1088/1752-7163/aa5524

\section{AUTHOR CONTRIBUTIONS}

BD'A, CP, MV, MR, PL, and AS have made a substantial, direct and intellectual contribution to the work, and approved it for publication.

\section{FUNDING}

This paper was supported through ordinary funding from the University of Naples Federico II.

18. Dospinescu V-M, Tiele A, Covington J. Sniffing out urinary tract infectiondiagnosis based on volatile organic compounds and smell profile. Biosensors. (2020) 10:83. doi: 10.3390/bios10080083

19. Grandjean D, Sarkis R, Lecoq-Julien C, Benard A, Roger V, Levesque E, et al. Can the detection dog alert on COVID-19 positive persons by sniffing axillary sweat samples? A proof-of-concept study. PLoS ONE. (2020) 15:e0243122. doi: 10.1371/journal.pone.0243122

20. Jendrny P, Schulz C, Twele F, Meller S, von Köckritz-Blickwede M, Osterhaus ADME, et al. Scent dog identification of samples from COVID-19 patients - a pilot study. BMC Infect Dis. (2020) 20:536. doi: 10.1186/s12879-020-05281-3

21. Vesga O, Valencia A, Mira A, Ossa F, Ocampo E, Agudelo M, et al. Dog Savior: immediate scent-detection of SARS-COV-2 by trained dogs. bioRxiv [Preprint]. (2020). doi: 10.1101/2020.06.17.158105

22. Balsam P, Tomie A. Context and Learning. Hillsdale, NJ: Lawrence Erlbaum Associates, Inc. (1985).

23. Gazit I, Goldblatt A, Terkel J. The role of context specificity in learning: the effects of training context on explosives detection in dogs. Anim Cogn. (2005) 8:143-50. doi: 10.1007/s10071-004-0236-9

24. Walczak M, Jezierski T, Górecka-Bruzda A, Sobczyńska M, Ensminger J. Impact of individual training parameters and manner of taking breath odor samples on the reliability of canines as cancer screeners. J Vet Behav Clin Appl Res. (2012) 7:283-94. doi: 10.1016/j.jveb.2012.01.001

25. Gould O, Ratcliffe N, Król E, De Lacy Costello B. Breath analysis for detection of viral infection, the current position of the field. J Breath Res. (2020) 14:041001. doi: 10.1088/1752-7163/ab9c32

26. Aksenov AA, Sandrock CE, Zhao W, Sankaran S, Schivo M, Harper R, et al. Cellular scent of influenza virus infection. ChemBioChem. (2014) 15:10401048. doi: 10.1002/cbic. 201300695

27. Steppert C, Steppert I, Sterlacci W, Bollinger T. Rapid detection of SARSCoV-2 infection by multicapillary column coupled ion mobility spectrometry (MCC-IMS) of breath. A proof of concept study. J Breath Res (2021). doi: 10.1088/1752-7163/abe5ca. [Epub ahead of print].

28. Angle TC, Passler T, Waggoner PL, Fischer TD, Rogers B, Galik PK, et al. Real-time detection of a virus using detection dogs. Front Vet Sci. (2016) 2:79. doi: $10.3389 /$ fvets.2015.00079

29. Grandjean D, Sarkis R, Tourtier JP, Julien-Lecocq C, Benard A, Roger V, et al. Detection dogs as a help in the detection of COVID-19 can the dog alert on COVID-19 positive persons by sniffing axillary sweat samples? Proof-ofconcept study. bioRxiv [Preprint]. (2020). doi: 10.1101/2020.06.03.132134

30. Ma L, Xie W, Li D, Shi L, Ye G, Mao Y, et al. Evaluation of sex-related hormones and semen characteristics in reproductive-aged male COVID-19 patients. J Med Virol. (2021) 93:456-62. doi: 10.1002/jmv.26259

31. Elliker KR, Sommerville BA, Broom DM, Neal DE, Armstrong S, Williams HC. Key considerations for the experimental training and evaluation of cancer odour detection dogs: lessons learnt from a double-blind, controlled trial of prostate cancer detection. BMC Urol. (2014) 14:22. doi: 10.1186/1471-2490-14-22

32. Jones RT, Guest C, Lindsay SW, Kleinschmidt I, Bradley J, Dewhirst S, et al. Could bio-detection dogs be used to limit the spread of COVID-19 by travellers? J Travel Med. (2020) 27:1-3. doi: 10.1093/jtm/taaa131

33. Wong G, Bi YH, Wang QH, Chen XW, Zhang ZG, Yao YG. Zoonotic origins of human coronavirus 2019 (HCoV-19/SARSCoV-2): why is this work important? Zool Res. (2020) 41:213-9. doi: $10.24272 /$ j.issn.2095-8137.2020.031 
34. Mahdy MAA, Younis W, Ewaida Z. An overview of SARS-CoV-2 and animal infection. Front Vet Sci. (2020) 7:596391. doi: 10.3389/fvets.2020.5 96391

35. Molenaar RJ, Vreman S, Hakze-van der Honing RW, Zwart R, de Rond J, Weesendorp E, et al. Clinical and pathological findings in SARS-CoV2 disease outbreaks in farmed mink (Neovison vison). Vet Pathol. (2020) 57:653-7. doi: 10.1177/0300985820943535

36. Deng J, Jin Y, Liu Y, Sun J, Hao L, Bai J, et al. Serological survey of SARSCoV-2 for experimental, domestic, companion and wild animals excludes intermediate hosts of 35 different species of animals. Transbound Emerg Dis. (2020) 67:1745-9. doi: 10.1111/tbed.13577

37. Bosco-Lauth AM, Hartwig AE, Porter SM, Gordy PW, Nehring M, Byas AD, et al. Experimental infection of domestic dogs and cats with SARS-CoV-2: pathogenesis, transmission, and response to reexposure in cats. Proc Natl Acad Sci USA. (2020) 117:26382-8. doi: 10.1073/pnas.2013102117

38. Patterson EI, Elia G, Grassi A, Giordano A, Desario C, Medardo M, et al. Evidence of exposure to SARS-CoV-2 in cats and dogs from households in Italy. Nat Commun. (2020) 11:6231. doi: 10.1038/s41467-020-20097-0

39. Fritz M, Rosolen B, Krafft E, Becquart P, Elguero E, Vratskikh O, et al. High prevalence of SARS-CoV-2 antibodies in pets from COVID-19+ households. One Heal. (2021) 11:0-4. doi: 10.1016/j.onehlt.2020.100192

40. Temmam S, Barbarino A, Maso D, Behillil S, Enouf V, Huon C, et al. Absence of SARS-CoV-2 infection in cats and dogs in close contact with a cluster of COVID-19 patients in a veterinary campus. bioRxiv [Preprint]. (2020). doi: 10.1101/2020.04.07.029090

41. Leroy EM, Ar Gouilh $M$, Brugère-Picoux J. The risk of SARS-CoV-2 transmission to pets and other wild and domestic animals strongly mandates a one-health strategy to control the COVID-19 pandemic. One Heal. (2020) 10:4-7. doi: 10.1016/j.onehlt.2020.100133

42. Loeb J. Pet dog confirmed to have coronavirus. Vet Rec. (2020) 186:265. doi: $10.1136 /$ vr.m892

43. Sit THC, Brackman CJ, Ip SM, Tam KWS, Law PYT, To EMW, et al. Infection of dogs with SARS-CoV-2. Nature. (2020) 586:776-8. doi: 10.1038/s41586-020-2334-5

44. Goumenou M, Spandidos DA, Tsatsakis A. Possibility of transmission through dogs being a contributing factor to the extreme Covid-19 outbreak in North Italy. Mol Med Rep. (2020) 21:2293-5. doi: 10.3892/mmr.2020.11037

45. Csiszar A, Jakab F, Valencak TG, Lanszki Z, Tóth GE, Kemenesi $\mathrm{G}$, et al. Companion animals likely do not spread COVID-19 but may get infected themselves. GeroScience. (2020) 42:1229-36. doi: $10.1007 /$ s11357-020-00248-3

46. Almendros A. Can companion animals become infected with Covid-19? Vet Rec. (2020) 186:388-9. doi: 10.1136/vr.m1194

47. Nikolich-Zugich J, Knox KS, Rios CT, Natt B, Bhattacharya D, Fain MJ. SARS-CoV-2 and COVID-19 in older adults: what we may expect regarding pathogenesis, immune responses, and outcomes. GeroScience. (2020) 42:50514. doi: 10.1007/s11357-020-00186-0

48. Shi J, Wen Z, Zhong G, Yang H, Wang C, Huang B, et al. Susceptibility of ferrets, cats, dogs, and other domesticated animals to SARS-coronavirus 2. Science. (2020) 368:1016-20. doi: 10.1126/science.abb7015

49. Stout AE, André NM, Jaimes JA, Millet JK, Whittaker GR. Coronaviruses in cats and other companion animals: Where does SARS-CoV-2/COVID-19 fit? Vet Microbiol. (2020) 247:108777. doi: 10.1016/j.vetmic.2020.108777

50. Xia X. Extreme genomic CpG deficiency in SARS-CoV-2 and evasion of host antiviral defense. Mol Biol Evol. (2020) 37:2699-705. doi: 10.1093/molbev/msaa094

51. van Oosterhout C, Hall N, Ly H, Tyler KM. COVID-19 evolution during the pandemic-Implications of new SARS-CoV-2 variants on disease control and public health policies. Virulence. (2021) 12:507-8. doi: 10.1080/21505594.2021.1877066

52. Woo PCY, Lau SKP, Huang Y, Yuen KY. Coronavirus diversity, phylogeny and interspecies jumping. Exp Biol Med. (2009) 234:1117-27. doi: 10.3181/0903-MR-94

53. Oude Munnink BB, Sikkema RS, Nieuwenhuijse DF, Jan Molenaar R, Munger E, Molenkamp R, et al. Jumping back and forth: anthropozoonotic and zoonotic transmission of SARS-CoV-2 on mink farms affiliations. bioRxiv [Preprint]. (2020). doi: 10.1101/2020.09.01.277152
54. Halfmann PJ, Hatta M, Chiba S, Maemura T, Fan S, Takeda M, et al. Transmission of SARS-CoV-2 in domestic cats. N Engl J Med. (2020) 383:5924. doi: 10.1056/NEJMc2013400

55. Sia SF, Yan LM, Chin AWH, Fung K, Choy KT, Wong AYL, et al. Pathogenesis and transmission of SARS-CoV-2 in golden hamsters. Nature. (2020) 583:8348. doi: 10.1038/s41586-020-2342-5

56. Chan JFW, Zhang AJ, Yuan S, Poon VKM, Chan CCS, Lee ACY, et al. Simulation of the clinical and pathological manifestations of coronavirus disease 2019 (COVID-19) in a golden Syrian hamster model: implications for disease pathogenesis and transmissibility. Clin Infect Dis. (2020) 71:2428-46. doi: $10.1093 / \mathrm{cid} / \mathrm{ciaa} 644$

57. Richard M, Kok A, de Meulder D, Bestebroer TM, Lamers MM, Okba NMA, et al. SARS-CoV-2 is transmitted via contact and via the air between ferrets. Nat Commun. (2020) 11:3496. doi: 10.1038/s41467-020-1 7367-2

58. Schlottau K, Rissmann M, Graaf A, Schön J, Sehl J, Wylezich C, et al. SARS-CoV-2 in fruit bats, ferrets, pigs, and chickens: an experimental transmission study. Lancet Microbe. (2020) 1:e218-225. doi: 10.1016/S2666-5247(20)30089-6

59. Suarez DL, Pantin-Jackwood MJ, Swayne DE, Lee SA, DeBlois SM, Spackman E. Lack of susceptibility to SARS-CoV-2 and MERS-CoV in poultry. Emerg Infect Dis. (2020) 26:3074-6. doi: 10.3201/eid2612.202989

60. Enserink M. Coronavirus rips through Dutc mink farms, triggering culls. Science. (2020) 368:1169. doi: 10.1126/science.368.6496.1169

61. Munnink BBO, Sikkema RS, Nieuwenhuijse DF, Molenaar RJ, Munger E, Molenkamp R, et al. Transmission of SARS-CoV-2 on mink farms between humans and mink and back to humans. Science. (2021) 371:172-7. doi: 10.1126/science.abe5901

62. Perisé-Barrios AJ, Tomeo-Martín BD, Gómez-Ochoa P, Delgado-Bonet P, Plaza P, Palau-Concejo P, et al. Humoral responses to SARS-CoV-2 by healthy and sick dogs during the COVID-19 pandemic in Spain. Vet Res. (2021) 52:22. doi: 10.1186/s13567-021-00897-y

63. Decaro N, Balboni A, Bertolotti L, Martino PA, Mazzei M, Mira F, et al. SARSCoV-2 infection in dogs and cats: facts and speculations. Front Vet Sci. (2021) 8:1-4. doi: 10.3389/fvets.2021.619207

64. Wölfel R, Corman VM, Guggemos W, Seilmaier M, Zange S, Müller $\mathrm{MA}$, et al. Virological assessment of hospitalized patients with COVID-2019. Nature. (2020) 581:465-9. doi: 10.1038/s41586-020-2 196-x

65. He H, Zhao S, Han L, Wang Q, Xia H, Huang X, et al. Anesthetic management of patients undergoing aortic dissection repair with suspected severe acute respiratory syndrome COVID-19 infection. J Cardiothorac Vasc Anesth. (2020) 34:1402-5. doi: 10.1053/j.jvca.2020.03.021

66. Fathizadeh H, Taghizadeh S, Safari R, Khiabani SS, Babak B, Hamzavi F, et al. Study presence of COVID-19 (SARS-CoV-2) in the sweat of patients infected with Covid-19. Microb Pathog. (2020) 149:104556. doi: 10.1016/j.micpath.2020.104556

67. Filetti V, Di Mizio G, Rendine M, Fortarezza P, Ricci P, Pomara C, et al. Volatile organic compounds: instrumental and canine detections link an individual to the crime scene. Egypt J Forensic Sci. (2019) 9:35. doi: 10.1186/s41935-019-0139-1

68. Cardinali FL, Mc Craw JM, Ashley DL, Bonin M, Wooten J. Treatment of vacutainers for use in the analysis of volatile organic compounds in human blood at the low parts-per-tri11ion level. J Chromatogr Sci. (1995) 33:557-60. doi: $10.1093 / \mathrm{chromsci} / 33.10 .557$

Conflict of Interest: The authors declare that the research was conducted in the absence of any commercial or financial relationships that could be construed as a potential conflict of interest.

Copyright (C) 2021 D'Aniello, Pinelli, Varcamonti, Rendine, Lombardi and Scandurra. This is an open-access article distributed under the terms of the Creative Commons Attribution License (CC BY). The use, distribution or reproduction in other forums is permitted, provided the original author(s) and the copyright owner(s) are credited and that the original publication in this journal is cited, in accordance with accepted academic practice. No use, distribution or reproduction is permitted which does not comply with these terms. 